\title{
Article \\ A Hierarchical Architecture of Functionalized Polyaniline/Manganese Dioxide Composite with Stable-Enhanced Electrochemical Performance
}

\author{
Yapeng Wang ${ }^{1,2}$, Yanxiang Wang ${ }^{1,2, *}$, Chengjuan Wang ${ }^{2}$ and Yongbo Wang ${ }^{2}$ \\ 1 Key Laboratory for Liquid-Solid Structural Evolution and Processing of Materials (Ministry of Education), \\ State Key Laboratory of Crystal Materials, Shandong University, Jinan 250061, China; \\ 202014149@mail.sdu.edu.cn \\ 2 Carbon Fiber Engineering Research Center, School of Materials Science and Engineering, \\ Shandong University, Jinan 250061, China; wcj3519@163.com (C.W.); Wangyapeng@163.com (Y.W.) \\ * Correspondence: wyx079@sdu.edu.cn
}

check for updates

Citation: Wang, Y.; Wang, Y.; Wang, C.; Wang, Y. A Hierarchical Architecture of Functionalized Polyaniline/Manganese Dioxide Composite with Stable-Enhanced Electrochemical Performance. J. Compos. Sci. 2021, 5, 129. https:// doi.org/10.3390/jcs5050129

Academic Editor:

Phuong Nguyen-Tri

Received: 30 March 2021

Accepted: 11 May 2021

Published: 13 May 2021

Publisher's Note: MDPI stays neutral with regard to jurisdictional claims in published maps and institutional affiliations.

Copyright: (c) 2021 by the authors. Licensee MDPI, Basel, Switzerland. This article is an open access article distributed under the terms and conditions of the Creative Commons Attribution (CC BY) license (https:/ / creativecommons.org/licenses/by/ $4.0 /)$.

\begin{abstract}
As one of the most outstanding high-efficiency and environmentally friendly energy storage devices, the supercapacitor has received extensive attention across the world. As a member of transition metal oxides widely used in electrode materials, manganese dioxide $\left(\mathrm{MnO}_{2}\right)$ has a huge development potential due to its excellent theoretical capacitance value and large electrochemical window. In this paper, $\mathrm{MnO}_{2}$ was prepared at different temperatures by a liquid phase precipitation method, and polyaniline/manganese dioxide $\left(\mathrm{PANI} / \mathrm{MnO}_{2}\right)$ composite materials were further prepared in a $\mathrm{MnO}_{2}$ suspension. $\mathrm{MnO}_{2}$ and $\mathrm{PANI} / \mathrm{MnO}_{2}$ synthesized at a temperature of $40{ }^{\circ} \mathrm{C}$ exhibit the best electrochemical performance. The specific capacitance of the sample $\mathrm{MnO}_{2}-40$ is $254.9 \mathrm{~F} / \mathrm{g}$ at a scanning speed of $5 \mathrm{mV} / \mathrm{s}$ and the specific capacitance is $241.6 \mathrm{~F} / \mathrm{g}$ at a current density of $1 \mathrm{~A} / \mathrm{g}$. The specific capacitance value of the sample $\mathrm{PANI} / \mathrm{MnO}_{2}-40$ is $323.7 \mathrm{~F} / \mathrm{g}$ at a scanning speed of $5 \mathrm{mV} / \mathrm{s}$, and the specific capacitance is $291.7 \mathrm{~F} / \mathrm{g}$ at a current density of $1 \mathrm{~A} / \mathrm{g}$, and both of them are higher than the specific capacitance value of $\mathrm{MnO}_{2}$. This is because the $\delta$ $\mathrm{MnO}_{2}$ synthesized at $40{ }^{\circ} \mathrm{C}$ has a layered structure, which has a large specific surface area and can accommodate enough electrolyte ions to participate the electrochemical reaction, thus providing sufficient specific capacitance.
\end{abstract}

Keywords: manganese dioxide; supercapacitors; polyaniline; electrochemical performance; specific capacitance

\section{Introduction}

With the depletion of fossil energy, global warming and the limited development of new energy, it has become an urgent task to develop a new environment-friendly energy storage device with high efficiency [1]. The supercapacitor has emerged through the joint efforts of researchers all over the world. It is considered to be the next -generation energy storage device with great development potential given that it has longer life, it is easier to manipulate, and it is more environment-friendly than fuel and secondary cells [2,3]. Electrode materials play a vital decisive role in supercapacitors' excellent performance, which include three types: carbon materials, conductive polymers and transition metal compounds [4]. As a representative of conductive polymers, polyaniline (PANI) has become a commonly used electrode material due to its simple synthesis process, low price and good electrical conductivity [5,6]. As a transition metal oxide, manganese dioxide $\left(\mathrm{MnO}_{2}\right)$ has great attraction as electrode material because of easy synthesis, nontoxic environmental protection and theoretical capacitance value, becoming a typical pseudocapacitive material [7,8].

Li et al. [9] published the theoretical and experimental specific capacitance of polyaniline in sulfuric acid. According to this, assuming that PANI reacts completely during 
charging and discharging, the maximum capacitance of PANI can reach $2000 \mathrm{~F} / \mathrm{g}$. Although PANI has many advantages, its electrical conductivity decreases due to electrode polarization and poor oxidation rate [10]. In addition, PANI will expand or contract after many cycles, and the electrochemical performance of PANI will be seriously affected. Therefore, it is often combined with other materials to improve the stability of the electrode material and to increase the practical application of the PANI electrodes. Researchers are now focusing on the preparation of composite materials to improve the structural stability.

Due to the unique valence changes of metal elements, transition metal compounds have a wide range of applications in the field of pseudocapacitance materials [11]. As a typical representative, $\mathrm{MnO}_{2}$ has attracted great attraction as an electrode material [12]. Various forms of manganese dioxide can be obtained under different process conditions. The most common crystal forms are: $\alpha-\mathrm{MnO}_{2}, \beta-\mathrm{MnO}_{2}, \gamma-\mathrm{MnO}_{2}, \delta-\mathrm{MnO}_{2}$ and $\lambda-\mathrm{MnO}_{2}$ [13]. These $\mathrm{MnO}_{2}$ isomers can be used in different fields according to their tunnel size, crystal system type, which gives full play to their respective advantages [14]. There is a large gap between the actual specific capacitance value and the theoretical specific capacitance value of $\mathrm{MnO}_{2}$, which limits its further applications. The development of efficient and stable $\mathrm{MnO}_{2}$ electrode materials is still a major challenge [15,16]. Kumar et al. [17] prepared $\mathrm{NiO} / \mathrm{MnO}_{2} \mathrm{NPs}$ on surfaces of reduced graphene oxide nanosheets (rGO NSs ) by microwave irradiation anchoring which has opened a novel route towards the simple and effective preparation of $\mathrm{MnO}_{2}$ electrode materials. Xie et al. [18] prepared a $\gamma-\mathrm{MnO}_{2} / \mathrm{PANI}$ composite electrode by in-situ synthesis technology, indicating that the composite material has great development prospects. Sun et al. [19] synthesized a binary composite material with a honeycomb structure of $\mathrm{MnO}_{2}$ nanospheres coated with a PANI layer. When the current density is $0.8 \mathrm{~A} / \mathrm{g}$, the capacity is $143 \mathrm{mAh} / \mathrm{g}$, after 1000 charge and discharge cycles, the electrode material retains about $77 \%$ of the initial capacitance.

In this paper, $\mathrm{MnO}_{2}$ was successfully synthesized by liquid phase precipitation and polyaniline/manganese dioxide $\left(\mathrm{PANI} / \mathrm{MnO}_{2}\right)$ composites were prepared in the suspensions of $\mathrm{MnO}_{2}$. The morphology, functional groups and electrochemical properties of the samples were analyzed. $\mathrm{MnO}_{2}$ was prepared with different temperatures, showing three different lattice structures of $\delta-\mathrm{MnO}_{2}, \alpha-\mathrm{MnO}_{2}$ and $\gamma-\mathrm{MnO}_{2}$, respectively. Herein, the liquid phase precipitation method was used, and manganese sulfate and potassium permanganate were used as raw materials to prepare $\mathrm{MnO}_{2}$ under different temperature conditions, and the influence of temperature on the surface morphology, crystal structure and electrochemical properties of $\mathrm{MnO}_{2}$ was explored. Afterwards, $\mathrm{PANI} / \mathrm{MnO}_{2}$ composite materials were prepared by in-situ polymerization of aniline in a suspension of $\mathrm{MnO}_{2}$, and the differences in morphology, structure and performance of different composite materials were explored.

\section{Materials and Methods}

\subsection{Preparation of Polyaniline (PANI)}

$2 \mathrm{~mL}$ of aniline was added into a three-necked bottle containing $100 \mathrm{~mL}$ of the deionized water. Then $10 \mathrm{~mL}$ of $2 \mathrm{~mol} / \mathrm{L}$ hydrochloric acid was added into it, and the mixture was stirred. Keeping the temperature of the water bath at $5{ }^{\circ} \mathrm{C}, 0.065 \mathrm{~g}$ of ammonium persulfate were weighed and dissolved in $50 \mathrm{~mL}$ of the deionized water, and then the solution was added dropwise to the three-necked flask with a separatory funnel, and the mixture was stirred for $6 \mathrm{~h}$ to complete the reaction. After the reaction, the precipitate was washed with the deionized water five times, and after filtration and drying under a vacuum, PANI was obtained. 


\subsection{Preparation of $\mathrm{MnO}_{2}$}

In this experiment, the liquid phase precipitation method was used to prepare $\mathrm{MnO}_{2}$ using potassium permanganate and manganese sulfate. The principle is shown in the following formula:

$$
3 \mathrm{MnSO}_{4}+2 \mathrm{KMnO}_{4}+2 \mathrm{H}_{2} \mathrm{O}=5 \mathrm{MnO}_{2} \downarrow+2 \mathrm{H}_{2} \mathrm{SO}_{4}+\mathrm{K}_{2} \mathrm{SO}_{4}
$$

We added $3 \mathrm{~g}$ of manganese sulfate to a three-necked flask containing $70 \mathrm{~mL}$ of the deionized water, and the mixture was stirred for $10 \mathrm{~min}$ to fully dissolve. $2.5 \mathrm{~g}$ of potassium permanganate was dissolved in $70 \mathrm{~mL}$ of the deionized water and then the solution was added dropwise to a three-necked flask with a separatory funnel to react. We set the temperature of the water bath to $40{ }^{\circ} \mathrm{C}, 50{ }^{\circ} \mathrm{C}, 60^{\circ} \mathrm{C}$ and $70{ }^{\circ} \mathrm{C}$, respectively, and the reaction time was $6 \mathrm{~h}$. After the reaction, the precipitate was washed with the deionized water five times. After filtration and drying under vacuum, $\mathrm{MnO}_{2}$ was obtained. The four groups of samples were named $\mathrm{MnO}_{2}-40, \mathrm{MnO}_{2}-50, \mathrm{MnO}_{2}-60$ and $\mathrm{MnO}_{2}-70$.

\subsection{Preparation of $\mathrm{PANI} / \mathrm{MnO}_{2}$ Composite}

We added $0.02 \mathrm{~g}$ of $\mathrm{MnO}_{2}$ into a three-necked bottle containing $100 \mathrm{~mL}$ of the deionized water, and a micro syringe was used to measure $20 \mu \mathrm{L}$ of aniline into it. Then $10 \mathrm{~mL}$ of $2 \mathrm{~mol} / \mathrm{L}$ hydrochloric acid and $1.2 \mathrm{~g}$ of PVP were added into it, and the mixture was stirred. Keeping the temperature of the water bath at $5^{\circ} \mathrm{C}, 0.065 \mathrm{~g}$ of ammonium persulfate were weighed and dissolved in $50 \mathrm{~mL}$ of the deionized water, and then the solution was added dropwise to the three-necked flask with a separatory funnel, and the mixture was stirred for $6 \mathrm{~h}$ to complete the reaction. The mass ratio of $\mathrm{MnO}_{2}$ to aniline was 1:1, and the $\mathrm{wt} \%$ of $\mathrm{MnO}_{2}$ in polyaniline was about $50 \%$. After the stirring stopped, the pure PANI/ $\mathrm{MnO}_{2}$ composite material could be obtained by washing with the hydrochloric acid twice and the deionized water three times by suction filtration, and vacuum drying. The four sets of $\mathrm{MnO}_{2}$ samples obtained previously were prepared in the same way as composite materials, and the four sets of samples were named after PANI/ $\mathrm{MnO}_{2}-40$, $\mathrm{PANI} / \mathrm{MnO}_{2}-50, \mathrm{PANI} / \mathrm{MnO}_{2}-60$ and $\mathrm{PANI} / \mathrm{MnO}_{2}-70$, respectively.

\subsection{Preparation of Electrode}

The working electrode was fabricated by mixing $0.8 \mathrm{~g}$ of PANI/ $\mathrm{MnO}_{2}$ composites, $0.1 \mathrm{~g}$ of acetylene black and $0.1 \mathrm{~g}$ of polytetrafluoroethylene (PTFE) binder in alcohol solvent under sonication to form a homogeneous slurry. After that, the slurry was coated on $1 \mathrm{~cm} \times 1 \mathrm{~cm}$ of nickel foam, and pressed for $1 \mathrm{~min}$ under a pressure of $15 \mathrm{MPa}$ to obtain an electrode sheet. Ensure that the mass of the active material on each electrode sheet was about $3 \mathrm{mg}$.

\subsection{Characterization}

The surface morphology and microstructure of the composite were observed by using a scanning electron microscope (SEM, SU-70). The Fourier transform infrared spectrum (FTIR, Vector 33) was obtained to analyze the absorption peak of functional groups, with the scanning range from 4000 to $400 \mathrm{~cm}^{-1}$ at room temperature. X-ray diffraction (XRD) was characterized to analyze the crystalline properties using $\mathrm{x}$-ray diffractometer (Rigaku $\mathrm{D} /$ max-RC) with $\mathrm{Cu} \mathrm{K} \alpha$ target in the $2 \theta$ range from $5^{\circ}$ to $70^{\circ}$. The electrochemical characterizations, such as cyclic voltammetry (CV) and galvanostatic charge-discharge (GCD), were performed using a potentiostatic electrochemical workstation (CHI660E) with the help of a three-electrode system. The electrochemical performance was measured in the aqueous electrolyte of $1 \mathrm{M} \mathrm{Na}_{2} \mathrm{SO}_{4}$. 


\section{Results and Discussion \\ 3.1. Surface Morphology Analysis}

Figure 1 shows the scanning electron microscope images of $\mathrm{MnO}_{2}$ prepared under different temperature conditions. The four groups of samples show different morphology. As shown in Figure 1a, $\mathrm{MnO}_{2}-40$ has a spherical shape with a diameter of about $200 \mathrm{~nm}$ and a relatively uniform morphology. In Figure $1 \mathrm{~b}, \mathrm{MnO}_{2}-50$ is irregular spherical, with linear structure on the surface, and agglomeration is more serious. After the reaction temperature rises, as shown in Figure $1 \mathrm{c}, \mathrm{MnO}_{2}-60$ presents a nanowire structure with a length less than $1 \mu \mathrm{m}$. The morphology is not uniform, with a little agglomeration. The nanowires pile up in clumps. In Figure $1 \mathrm{~d}, \mathrm{MnO}_{2}-70$ has a sheet-like structure, which shows its agglomeration. Due to the difference in reaction temperature, the crystallization process of $\mathrm{MnO}_{2}$ is influenced, and different lattice structures are formed, showing the different morphological characteristics $[20,21]$.
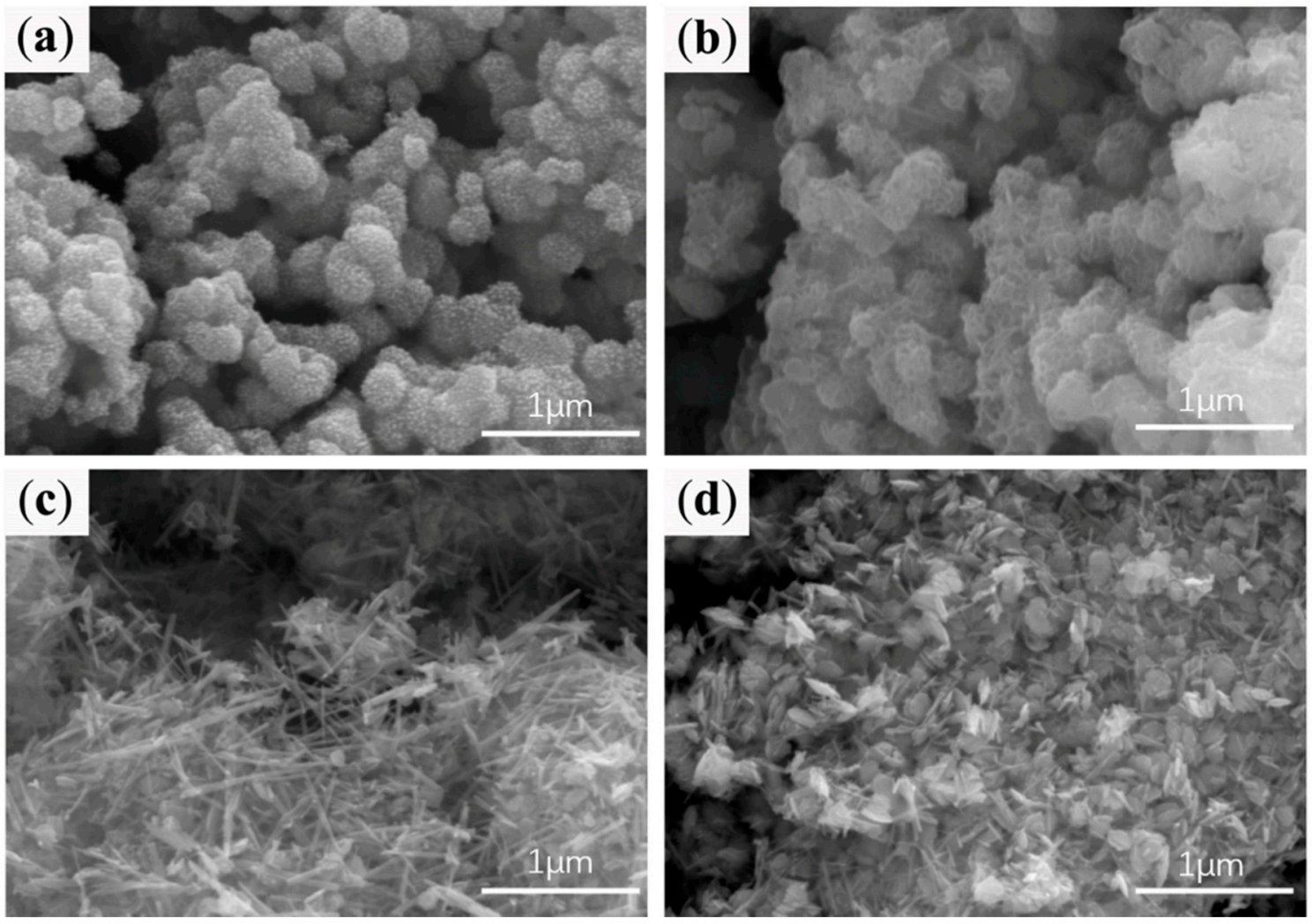

Figure 1. Scanning electron microscope (SEM) images of $\mathrm{MnO}_{2}$ : (a) $\mathrm{MnO}_{2}-40$, (b) $\mathrm{MnO}_{2}-50$, (c) $\mathrm{MnO}_{2}-60$, (d) $\mathrm{MnO}_{2}-70$.

Figure 2 is a SEM of PANI $/ \mathrm{MnO}_{2}$ composite material, which shows different morphology of the four groups of samples. As shown in Figure 2a, PANI/ $\mathrm{MnO}_{2}-40$ sample has a flaky structure on the basis of the spherical shape, which is caused by the presence of PANI, the mixture of flaky and spherical shapes is relatively uniform. In Figure 2b, $\mathrm{PANI} / \mathrm{MnO}_{2}-50$ is an irregular spherical shape, and the agglomeration phenomenon is very serious. As shown in Figure 2c, PANI/ $\mathrm{MnO}_{2}-60$ presents a agglomeration, and the linear structure of $\mathrm{MnO}_{2}-60$ cannot be seen. This is due to the high degree of polymerization of PANI, which covers $\mathrm{MnO}_{2}$. Therefore, it is difficult to show its appearance. In Figure 2d, the sheet structure of PANI/ $\mathrm{MnO}_{2}-70$ is more obvious, and the agglomeration phenomenon is more serious. Because the particle size of $\mathrm{MnO}_{2}$ is very small, the polymerization of aniline in its suspension is prone to the agglomeration of PANI, and it is difficult to control the morphology of the composite material [22,23]. 

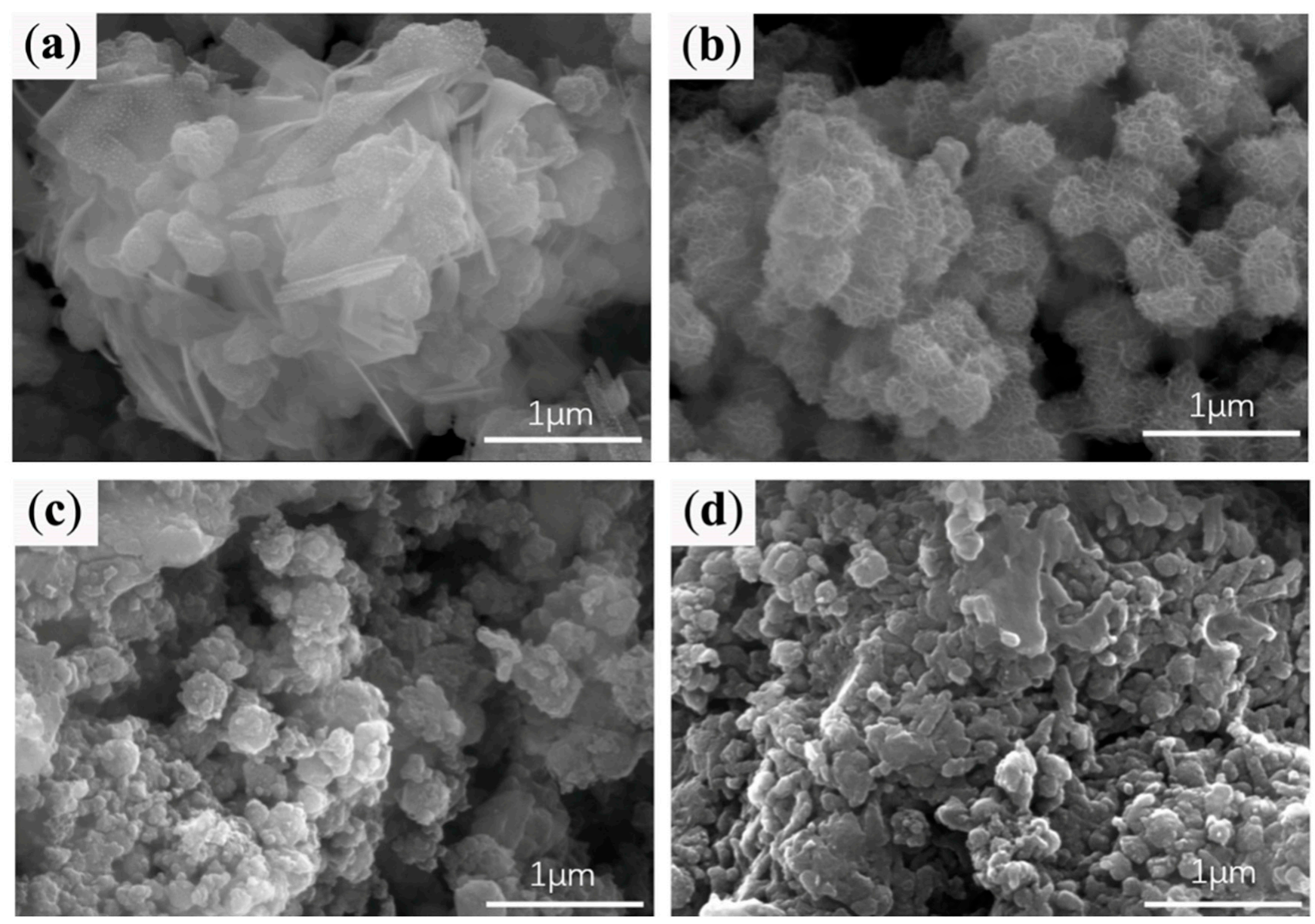

Figure 2. SEM images of polyaniline (PANI) $/ \mathrm{MnO}_{2}$ composite (a) $\mathrm{PANI} / \mathrm{MnO}_{2}-40$, (b) $\mathrm{PANI} / \mathrm{MnO}_{2}-50$, (c) $\mathrm{PANI} / \mathrm{MnO}_{2}-60$, (d) $\mathrm{PANI} / \mathrm{MnO}_{2}-70$.

\subsection{Chemical Structure Analysis of $\mathrm{MnO}_{2}$ and PANI/MnO $\mathrm{M}_{2}$ Composite}

Figure 3 shows FTIR spectra of $\mathrm{MnO}_{2}$ samples. The four groups of samples all show the strong infrared absorption peaks near $520 \mathrm{~cm}^{-1}$, manifesting the vibration of the $\mathrm{Mn}-\mathrm{O}$ bond [24]. In the infrared spectra of $\mathrm{MnO}_{2}-40$ and $\mathrm{MnO}_{2}-50$, the obvious infrared peaks appear at $3340 \mathrm{~cm}^{-1}$ and $1637 \mathrm{~cm}^{-1}$, respectively, representing the vibration of the $\mathrm{O}-\mathrm{H}$ bond [25] and the crystal of $\delta-\mathrm{MnO}_{2}$. The lattice is a layered structure, and there are water molecules and cations between the layers, so the absorption peak of hydroxyl appears. Because $\alpha-\mathrm{MnO}_{2}$ and $\gamma-\mathrm{MnO}_{2}$ belong to the tunnel structure, there are only oxygen and manganese atoms in the molecule, and the infrared absorption peak of the hydroxyl group does not appear [26]. Through infrared spectrum analysis, the crystalline form of $\mathrm{MnO}_{2}$ has been further verified.

Figure 4 shows FTIR spectra of PANI/ $\mathrm{MnO}_{2}$ composite materials. It can be found that the infrared peaks at $1150 \mathrm{~cm}^{-1}, 1310 \mathrm{~cm}^{-1}, 1490 \mathrm{~cm}^{-1}$ and $1580 \mathrm{~cm}^{-1}$ correspond to the $\mathrm{C}=\mathrm{N}$ bond of the quinone ring, the $\mathrm{C}-\mathrm{N}$ bond of the benzene ring, the $\mathrm{C}=\mathrm{C}$ bond of the benzene ring and the $\mathrm{C}=\mathrm{C}$ bond of the quinone ring, respectively, which shows the typical infrared absorption peak of PANI. In the fingerprint vibration zone, the infrared absorption peak of the $\mathrm{Mn}-\mathrm{O}$ bond remains near $520 \mathrm{~cm}^{-1}$, which further confirms the coexistence of PANI and $\mathrm{MnO}_{2}$ in the composite. Combined with SEM analysis, it can be seen that there are more PANI agglomerations in the samples PANI/ $\mathrm{MnO}_{2}-60$ and PANI/ $\mathrm{MnO}_{2}-70$, which make the infrared absorption peak of PANI in the composite material more obvious. 


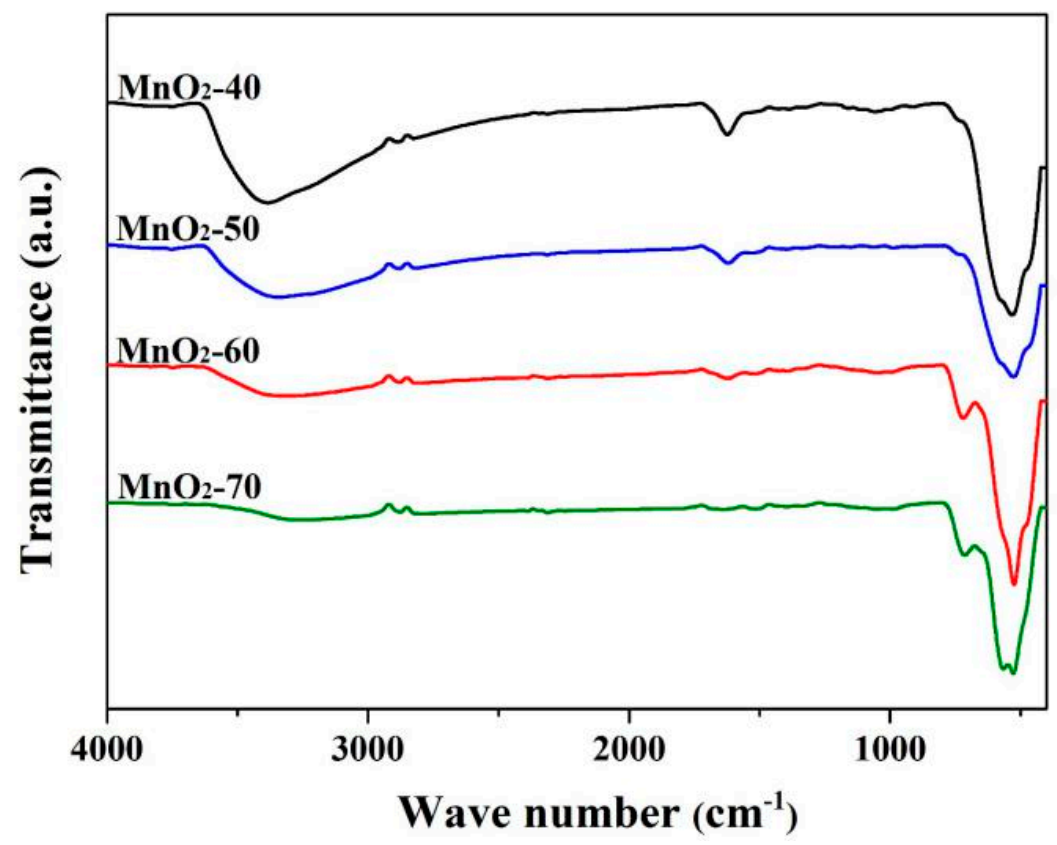

Figure 3. Fourier transform infrared (FTIR) spectra of $\mathrm{MnO}_{2}$ prepared at different temperatures.

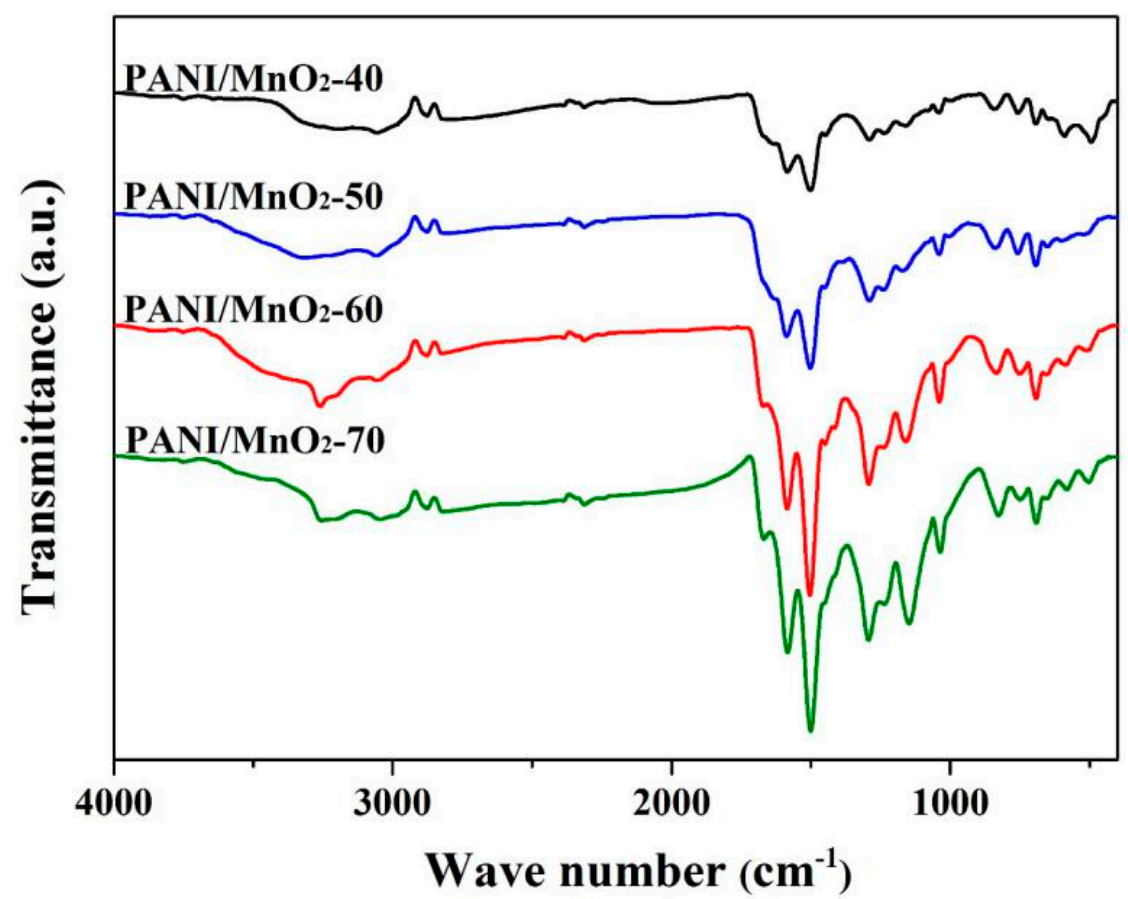

Figure 4. FTIR spectra of PANI/ $\mathrm{MnO}_{2}$ composites.

\subsection{X-ray Diffraction (XRD) Analysis of $\mathrm{MnO}_{2}$ and PANI/MnO $\mathrm{M}_{2}$ Composite}

Figure 5 shows XRD patterns of four groups of $\mathrm{MnO}_{2}$ samples. $\mathrm{MnO}_{2}-40$ and $\mathrm{MnO}_{2}-50$, both of them show the same crystalline characteristics, with four obvious diffraction peaks (JCPDS: 80-1098) near $2 \theta=11.5^{\circ}, 23.7^{\circ}, 37.8^{\circ}$ and $66.9^{\circ}$, corresponding to the vibrations of the four groups of crystal planes of $\mathrm{MnO}_{2}(001),(002),(100)$ and (110), respectively, which are the lattice structure of $\delta-\mathrm{MnO}_{2}$ [13]. $\mathrm{MnO}_{2}-60$ has diffraction peaks (JCPDS: 44-0141) near $2 \theta=12.3^{\circ}, 19.2^{\circ}, 28.7^{\circ}, 37.8^{\circ}, 42.1^{\circ}, 49.7^{\circ}, 58.8^{\circ}, 65.3^{\circ}$ and $69.6^{\circ}$, corresponding to the vibration of $\mathrm{MnO}_{2}$ (110), (200), (310), (211), (301), (411), (521), (002) and (541) crystal planes, respectively, showing the lattice structure of $\alpha-\mathrm{MnO}_{2}[26,27]$. The sample $\mathrm{MnO}_{2}-70$ shows diffraction peaks (JCPDS: $14-0644$ ) near $2 \theta=22.7^{\circ}, 37.9^{\circ}, 42.5^{\circ}, 56.2^{\circ}$ and $68.1^{\circ}$, correspond- 
ing to $\mathrm{MnO}_{2}$ (120), (131), (300), (160) and (421) crystal plane vibrations, respectively, which are the lattice structure of $\gamma-\mathrm{MnO}_{2}$ [18]. The diffraction peaks of the four groups of $\mathrm{MnO}_{2}$ samples are relatively strong, showing a good crystallization performance.

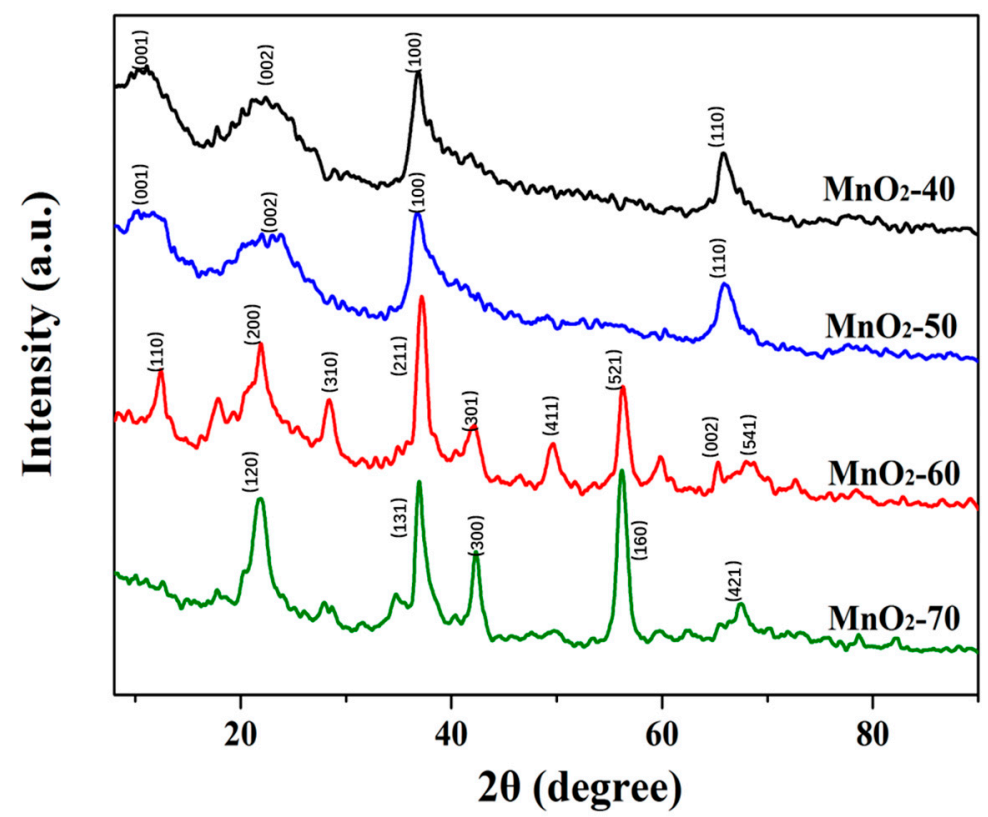

Figure 5. X-ray diffraction (XRD) patterns of $\mathrm{MnO}_{2}$ prepared at different temperatures.

Figure 6 shows XRD patterns of PANI/ $\mathrm{MnO}_{2}$ composite materials. Due to the joint action of PANI and $\mathrm{MnO}_{2}$, the diffraction peak intensity of the composite material between $20^{\circ}-25^{\circ}$ increases and the peak shape becomes wider, reflecting the diffraction characteristics of PANI. The other diffraction peaks of the composite material correspond to the $\mathrm{MnO}_{2}$ respectively, and the position do not change, but the intensity is different, still showing the different crystalline characteristics of $\mathrm{MnO}_{2}$, which also proves that PANI and $\mathrm{MnO}_{2}$ were successfully recombined. On the whole, due to the presence of PANI, the crystallization performance of the composite material has decreased.

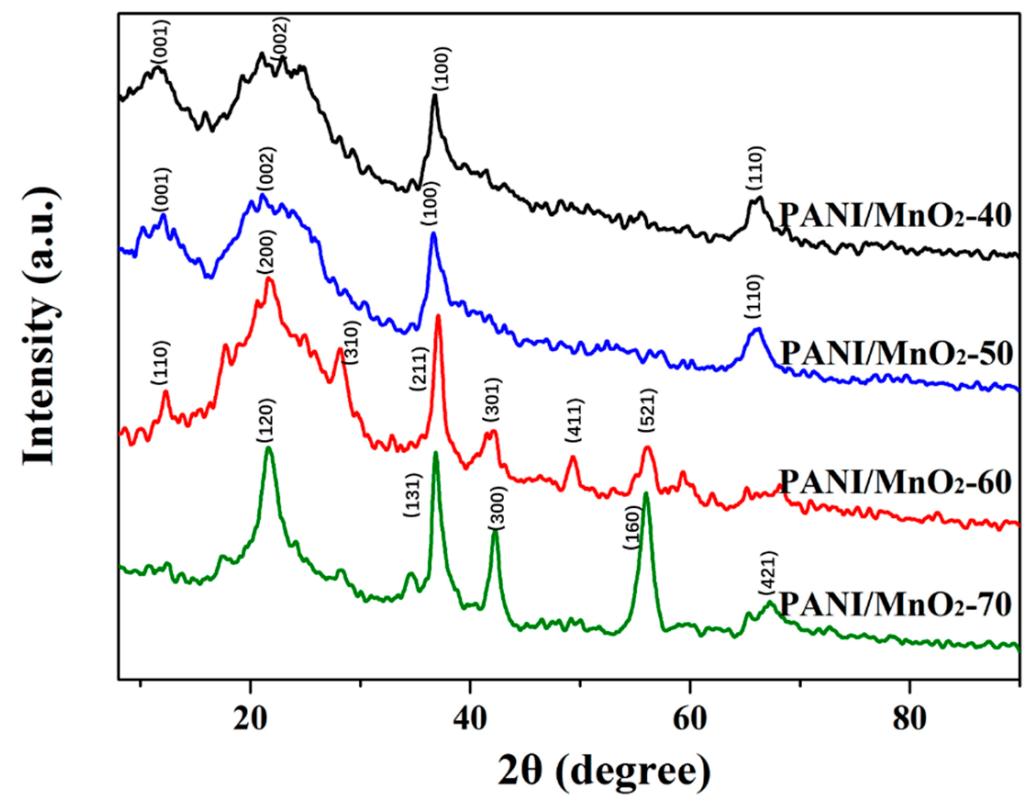

Figure 6. XRD patterns of $\mathrm{PANI} / \mathrm{MnO}_{2}$ composites. 


\subsection{Electrochemical Characterization}

Figure 7 shows the electrochemical performance of PANI. Figure 7a shows the CV curve of PANI at a scanning speed of $5 \mathrm{mV} / \mathrm{s}$. Calculated by Formula (1), the capacitance value of PANI is $197.3 \mathrm{~F} / \mathrm{g}$. Figure $7 \mathrm{~b}$ shows the GCD curve of PANI at the current density of $1 \mathrm{~A} / \mathrm{g}$. The capacitance value of PANI calculated by Formula (2) is 98.7 F/g.

$$
C_{m}=\frac{1}{v \cdot m \cdot \Delta V} \int i(V) d V
$$
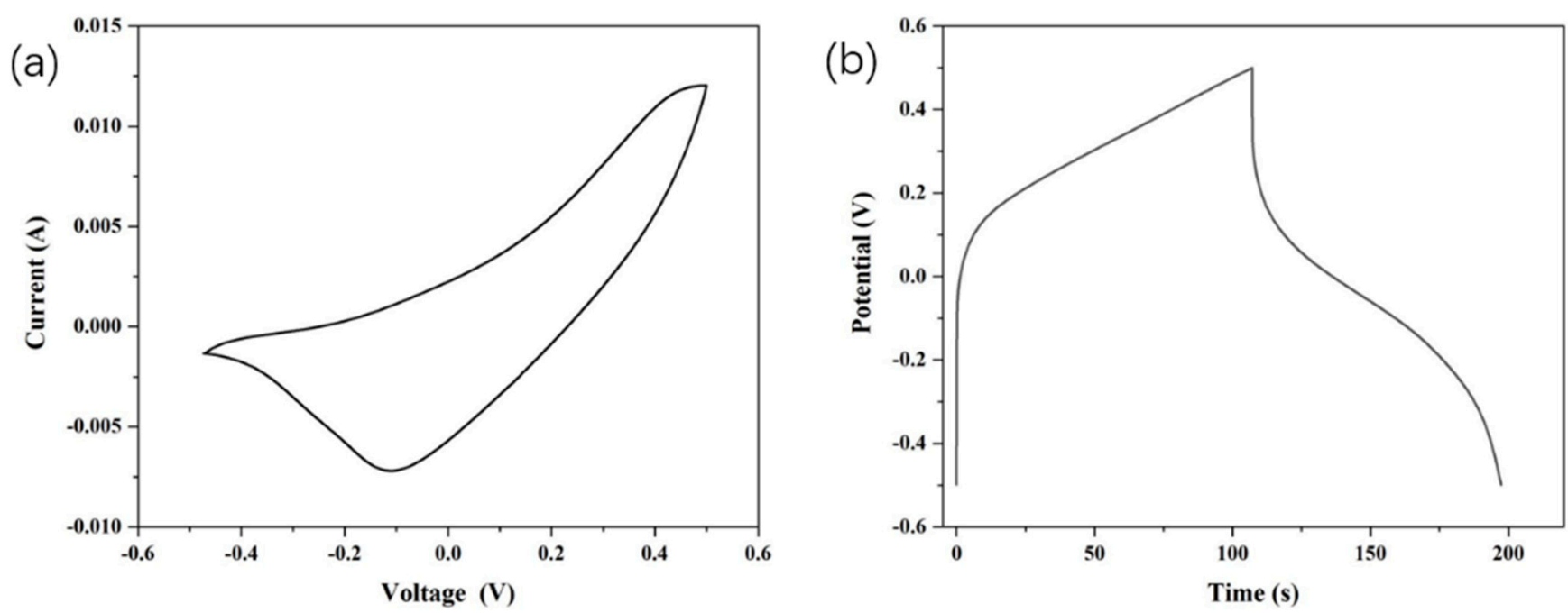

Figure 7. PANI: (a) cyclic voltammetry (CV) profile at the scan rate of $5 \mathrm{mV} / \mathrm{s}$, (b) galvanostatic charge-discharge (GCD) profile at the current density of $1 \mathrm{~A} / \mathrm{g}$.

In the Formula, $C_{m}(\mathrm{~F} / \mathrm{g})$ is the mass specific capacitance, $v(\mathrm{mV} / \mathrm{s})$ is the scan rate, $m$ (g) is the mass of the active material, $i$ (A) is the current that varies with voltage, and $\Delta V$ $(\mathrm{V})$ is voltage range.

$$
C_{m}=\frac{i \cdot \Delta t}{m \cdot \Delta V}
$$

In the Formula, $C_{m}(\mathrm{~F} / \mathrm{g})$ is the mass specific capacitance, $\Delta t(\mathrm{~s})$ is the discharge time, $m(\mathrm{~g})$ is the mass of the active material, $i(\mathrm{~A})$ is the current that varies with voltage, and $\Delta V$ $(\mathrm{V})$ is the voltage interval.

Figure 8 reflects the electrochemical performance of four groups of $\mathrm{MnO}_{2}$ samples. The $\mathrm{CV}$ curves at a scanning speed of $5 \mathrm{mV} / \mathrm{s}$ are shown in Figure $8 \mathrm{a}$. The four sets of curves have similar shapes, and all have a set of redox peaks, manifesting the valence changes of manganese in the electrochemical process [28]. $\mathrm{MnO}_{2}$ is a kind of pseudocapacitance electrode material. As a transition metal element, manganese will change valence during the electrochemical process. Among them, the area enclosed by the CV curve of $\mathrm{MnO}_{2}$ 40 is the largest, showing the highest specific capacitance of $254.9 \mathrm{~F} / \mathrm{g}$. As shown in Figure $8 \mathrm{~b}$, the specific capacitance of the other three groups of samples are $240.3 \mathrm{~F} / \mathrm{g}$, $227.6 \mathrm{~F} / \mathrm{g}$ and $216.1 \mathrm{~F} / \mathrm{g}$, respectively. The specific capacitance values of the four groups of samples are slightly different, which is caused by the different lattice structure of $\mathrm{MnO}_{2}$. $\delta-\mathrm{MnO}_{2}$ has a layered structure, and electrolyte ions can enter the interlayer, so it has a better electrochemical activity [29]. For the GCD curves at a current density of $1 \mathrm{~A} / \mathrm{g}$ as shown in Figure 8c, the four sets of curves show similar electrochemical processes, and the discharge time is different, which leads to differences in their specific capacitance values. Figure $8 \mathrm{~d}$ is the specific capacitance diagram under the current density of $1 \mathrm{~A} / \mathrm{g}$. The specific capacitances of the four groups of samples are $241.6 \mathrm{~F} / \mathrm{g}, 230.4 \mathrm{~F} / \mathrm{g}, 195.2 \mathrm{~F} / \mathrm{g}$ and $182.7 \mathrm{~F} / \mathrm{g} . \mathrm{MnO}_{2}-40$ shows the highest specific capacitance value. 

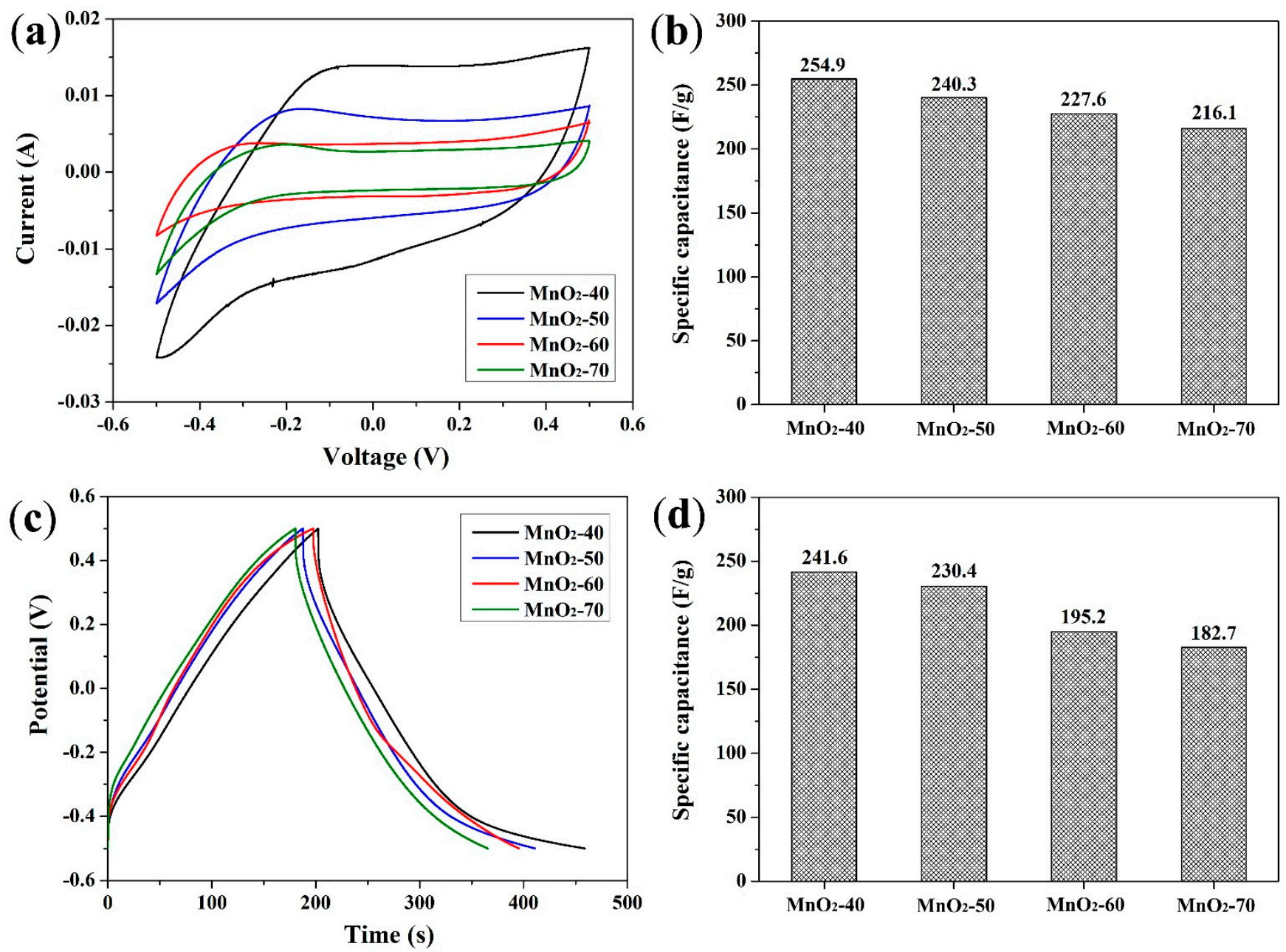

Figure 8. $\mathrm{MnO}_{2}$ prepared at different temperature: (a) $\mathrm{CV}$ profiles at the scan rate of $5 \mathrm{mV} / \mathrm{s}$, (b) the plot of specific capacitance at the scan rate of $5 \mathrm{mV} / \mathrm{s},(\mathbf{c}) \mathrm{GCD}$ profiles at the current density of $1 \mathrm{~A} / \mathrm{g}$, (d) the plot of specific capacitance at current density of $1 \mathrm{~A} / \mathrm{g}$.

Figure 9 reflects the electrochemical performance of PANI/ $\mathrm{MnO}_{2}$ composites. The $\mathrm{CV}$ curves at a scanning speed of $5 \mathrm{mV} / \mathrm{s}$ are shown in Figure $9 \mathrm{a}$, reflecting the valence change of manganese in the electrochemical process. However, compared with the redox peaks of $\mathrm{MnO}_{2}$, those of PANI/ $\mathrm{MnO}_{2}-40$ and PANI/ $\mathrm{MnO}_{2}-50$ become weaker. Meanwhile, the redox peaks of PANI $/ \mathrm{MnO}_{2}-60$ become stronger, and those of PANI/ $\mathrm{MnO}_{2}-70$ have almost no change. These different changes are due to PANI with different morphology and degree of agglomeration [30]. As shown in Figure 9b, it can be concluded that the specific capacitance of the four groups of samples are $323.7 \mathrm{~F} / \mathrm{g}, 311.4 \mathrm{~F} / \mathrm{g}, 286.5 \mathrm{~F} / \mathrm{g}$ and $279.3 \mathrm{~F} / \mathrm{g}$, respectively. All of them are higher than that of $\mathrm{MnO}_{2}$ samples, which is due to the common contribution of PANI and $\mathrm{MnO}_{2}$ to the electrochemical process. The synergistic effect of PANI and $\mathrm{MnO}_{2}$ enhances the electrochemical activity and thereby increases the specific capacitance. Figure $9 \mathrm{c}$ is the GCD curve at the current density of $1 \mathrm{~A} / \mathrm{g}$. The charge and discharge curves of the four groups of composite materials are different, and the charge and discharge time are obviously different. The sample PANI/ $\mathrm{MnO}_{2}-40$ has the longest discharge time, and its specific capacitance value is highest, which can reach up to $291.7 \mathrm{~F} / \mathrm{g}$. As shown in Figure 9d, the specific capacitance of the other three groups of samples are $276.5 \mathrm{~F} / \mathrm{g}, 247.4 \mathrm{~F} / \mathrm{g}$ and $239.2 \mathrm{~F} / \mathrm{g}$, respectively, which is higher than the specific capacitance of the corresponding. Through electrochemical performance analysis, it can be proved that PANI and $\mathrm{MnO}_{2}$ interact synergistically in the electrochemical process 
of composite materials, which jointly promote ion transfer, improved the electrochemical activity, and then show an excellent electrochemical performance [31].
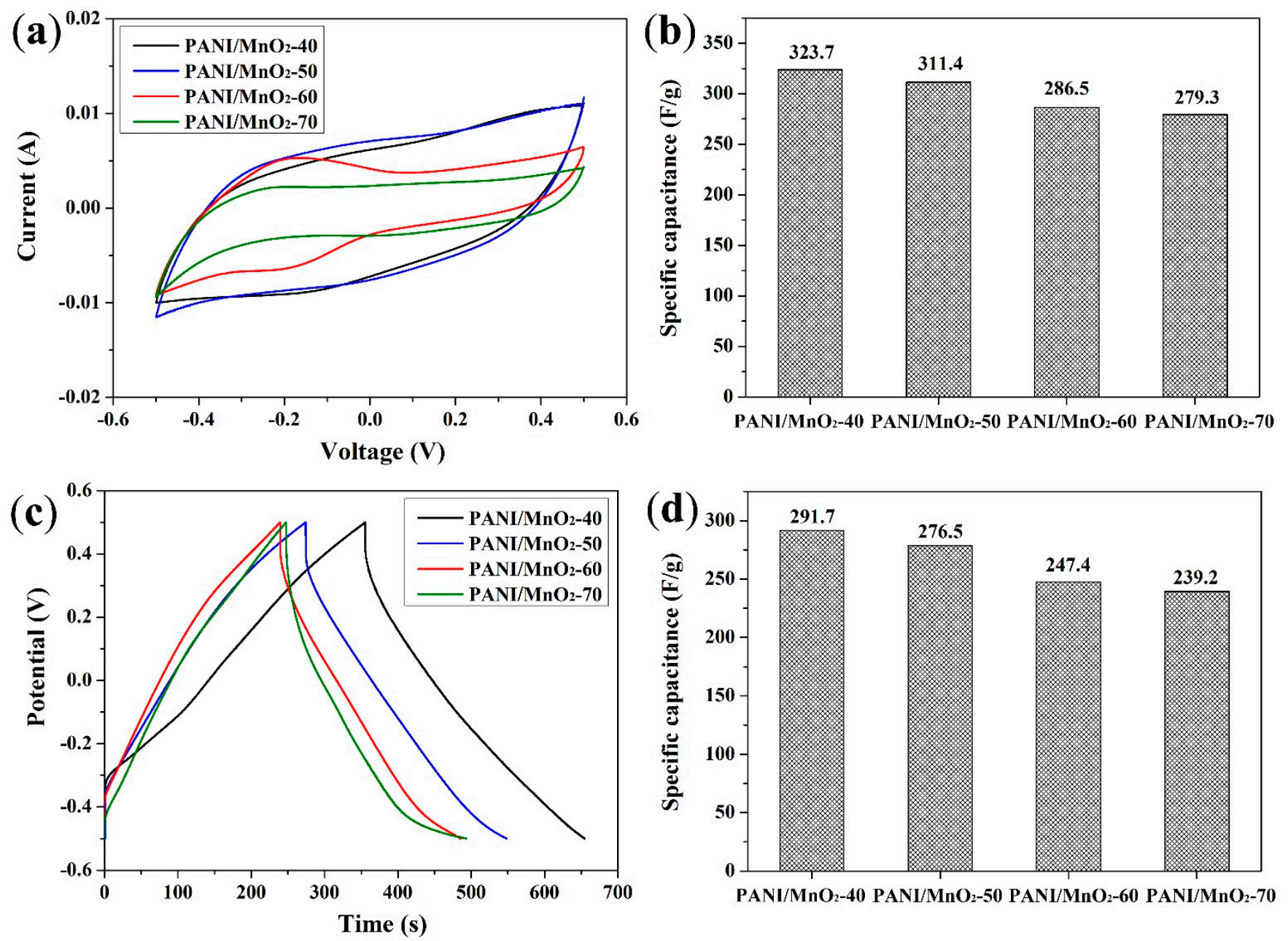

Figure 9. PANI/ $\mathrm{MnO}_{2}$ composite: (a) $\mathrm{CV}$ profiles at the scan rate of $5 \mathrm{mV} / \mathrm{s}$, (b) the plot of specific capacitance at the scan rate of $5 \mathrm{mV} / \mathrm{s}$, (c) GCD profiles at the current density of $1 \mathrm{~A} / \mathrm{g}$, (d) the plot of specific capacitance at current density of $1 \mathrm{~A} / \mathrm{g}$.

The addition of $\mathrm{MnO}_{2}$ can solve the problem of poor cycle stability. As a transition metal oxide, $\mathrm{MnO}_{2}$ can undergo the redox reactions in a suitable voltage range, and has some high capacitance and energy density [32], which has a mesoporous structure and a high specific surface area, and the pore size distribution is uniform. The interaction between the electrode and the electrolyte can promote the rapid transmission of ions, which leads to a pseudocapacitance much higher than the double-layer capacitance [33].

In addition, the direct addition of $\mathrm{MnO}_{2}$ during the polymerization of aniline can make polyaniline uniformly coat the outside of the $\mathrm{MnO}_{2}$ nanoparticles, forming a "shellcore structure", so that the two have a better coordination on the nano-scale, and in nano-composite. Thus, the material exerts a better synergistic effect and improves the electrochemical performance of the composite material [34].

Table 1 shows the comparison of different PANI/ $\mathrm{MnO}_{2}$ materials. It can see that the PANI/ $\mathrm{MnO}_{2}$ synthesized in this article is not only simple in synthesis method, but also high in capacitance. 
Table 1. Comparison among different PANI/MnO 2 samples.

\begin{tabular}{|c|c|c|c|c|}
\hline Material & Synthesis Method & Capacitance & Electrolyte & Ref. No. \\
\hline $\mathrm{PANI} / \alpha-\mathrm{MnO}_{2}$ & in-situ polymerization & 75 F/g (0.1 A/g) & $1 \mathrm{M} \mathrm{Na}_{2} \mathrm{SO}_{4}$ & {$[35]$} \\
\hline $\begin{array}{l}\text { sandwich-structured } \\
\mathrm{MnO}_{2} / \mathrm{PANI} / \mathrm{MnO}_{2}\end{array}$ & $\begin{array}{l}\text { electrochemical deposition and } \\
\text { in-situ polymerization }\end{array}$ & $214 \mathrm{~F} / \mathrm{g}(0.5 \mathrm{~A} / \mathrm{g})$ & $0.5 \mathrm{M} \mathrm{Na}_{2} \mathrm{SO}_{4}$ & [36] \\
\hline$\delta-\mathrm{MnO}_{2} / \mathrm{PANI}$ & $\begin{array}{l}\text { liquid phase precipitation and } \\
\text { in-situ polymerization }\end{array}$ & $291.7 \mathrm{~F} / \mathrm{g}(1 \mathrm{~A} / \mathrm{g})$ & $1 \mathrm{M} \mathrm{Na}_{2} \mathrm{SO}_{4}$ & This work \\
\hline
\end{tabular}

\section{Conclusions}

In conclusion, $\mathrm{MnO}_{2}$ was synthesized by the liquid phase precipitation method, the $\mathrm{PANI} / \mathrm{MnO}_{2}$ composite materials was successfully prepared in the manganese dioxide suspension. $\mathrm{MnO}_{2}$ prepared by liquid phase precipitation method under different temperature conditions show three different lattice structures: $\delta-\mathrm{MnO}_{2}, \alpha-\mathrm{MnO}_{2}$ and $\gamma-\mathrm{MnO}_{2}$. $\mathrm{MnO}_{2}-40$ is spherical, $\mathrm{MnO}_{2}-50$ is irregular spherical, $\mathrm{MnO}_{2}-60$ is nanowire structure, and $\mathrm{MnO}_{2}-70$ is sheet structure, respectively. The four groups of $\mathrm{MnO}_{2}$ samples all have a set of redox peaks, manifesting the valence changes of manganese in the electrochemical process. The specific capacitance of the sample $\mathrm{MnO}_{2}-40$ is the highest, with a specific capacitance of $254.9 \mathrm{~F} / \mathrm{g}$ at a scanning speed of $5 \mathrm{mV} / \mathrm{s}$ and a specific capacitance of $241.6 \mathrm{~F} / \mathrm{g}$ at a current density of $1 \mathrm{~A} / \mathrm{g}$. Due to the layered structure of $\delta-\mathrm{MnO}_{2}$, electrolyte ions can enter between the layers to obtain better electrochemical activity. The redox peaks of the four groups of composite materials are different from those of the $\mathrm{MnO}_{2}$ samples, but they all show the valence changes of manganese in the electrochemical process. The specific capacitance value of the sample PANI/ $\mathrm{MnO}_{2}-40$ is the highest, the specific capacitance is $323.7 \mathrm{~F} / \mathrm{g}$ at a scanning speed of $5 \mathrm{mV} / \mathrm{s}$, and the specific capacitance is $291.7 \mathrm{~F} / \mathrm{g}$ at a current density of $1 \mathrm{~A} / \mathrm{g}$. Compared with some previous work, our work exhibits the merits of low-cost, simple preparation, low energy consumption, high material stability, green chemistry and straightforward scale-up production.

Author Contributions: Conceptualization, Y.W. (Yapeng Wang) and Y.W. (Yanxiang Wang); Data curation, Y.W. (Yapeng Wang); Funding acquisition, Y.W. (Yanxiang Wang); Investigation, Y.W. (Yapeng Wang); Methodology, Y.W. (Yapeng Wang); Project administration, Y.W. (Yanxiang Wang); Software, C.W. and Y.W. (Yongbo Wang); Supervision, Y.W. (Yanxiang Wang); Validation, Y.W. (Yapeng Wang); Visualization, Y.W. (Yapeng Wang); Writing-original draft, Y.W. (Yapeng Wang); Writing-review and editing, Y.W. (Yapeng Wang), Y.W. (Yanxiang Wang), C.W. and Y.W. (Yongbo Wang). All authors have read and agreed to the published version of the manuscript.

Funding: This research was funded by Natural Science Foundation in Shandong Province (ZR2020ME039, ZR2020ME134) and National Natural Science Foundation of China (51773110).

Institutional Review Board Statement: Not applicable.

Informed Consent Statement: Not applicable.

Acknowledgments: The authors thank the editor and the anonymous reviewers for their valuable comments on this manuscript. The authors also acknowledge the support of technical staff for assisting in preparing samples and analyzing them.

Conflicts of Interest: The authors declare no conflict of interest.

\section{References}

1. Chen, X.; Paul, R.; Dai, L. Carbon-based supercapacitors for efficient energy storage. Natl. Sci. Rev. 2017, 4, 453-489. [CrossRef]

2. Zhang, A.; Gao, R.; Hu, L.; Zang, X.; Yang, R.; Wang, S.; Yao, S.; Yang, Z.; Hao, H.; Yan, Y. Rich bulk oxygen Vacancies-Engineered $\mathrm{MnO}_{2}$ with enhanced charge transfer kinetics for supercapacitor. Chem. Eng. J. 2021, 417, 129186. [CrossRef]

3. Wang, A.; Sun, K.; Xu, R.; Sun, Y.; Jiang, J. Cleanly synthesizing rotten potato-based activated carbon for supercapacitor by self-catalytic activation. J. Clean. Prod. 2021, 283, 125385. [CrossRef]

4. Kumar, R.; Joanni, E.; Singh, R.K.; Singh, D.P.; Moshkalev, S.A. Recent advances in the synthesis and modification of carbon-based 2D materials for application in energy conversion and storage. Prog. Energy Combust. Sci. 2018, 67, 115-157. [CrossRef] 
5. Gibot, P.; Goetz, V. $\mathrm{SnO}_{2}$-polyaniline composites for the desensitization of $\mathrm{Al} / \mathrm{SnO}_{2}$ thermite composites. J. Appl. Polym. Sci. 2020, 137, 48947. [CrossRef]

6. Dinh, H.N.; Vanýsek, P.; Birss, V.I. The Effect of Film Thickness and Growth Method on Polyaniline Film Properties. J. Electrochem. Soc. 2019, 146, 3324-3334. [CrossRef]

7. Yang, Q.; Li, Q.; Li, L.; Peng, Y.; Wang, D.; Ma, Y.; Li, J. Synthesis of $\alpha-\mathrm{MnO}_{2}$-like rod catalyst using $\mathrm{YMn}_{2} \mathrm{O}_{5} \mathrm{~A}-\mathrm{site}$ sacrificial strategy for efficient benzene oxidation. J. Hazard. Mater. 2021, 403, 123811. [CrossRef]

8. Thatikayala, D.; Deepak, P.; Booki, M. $\mathrm{MnO}_{2}$ /reduced graphene oxide nanohybrids as a cathode catalyst for the microbial reduction of $\mathrm{CO}_{2}$ to acetate and isobutyric acid. Sustain. Energy Technol. Assess. 2021, 45, 101114.

9. Li, H.; Wang, J.; Chu, Q.; Wang, Z.; Zhang, F.; Wang, S. Theoretical and experimental specific capacitance of polyaniline in sulfuric acid. J. Power Sources 2009, 190, 578-586. [CrossRef]

10. Geng, J.-Y.; Ye, Y.-J.; Guo, D.; Liu, X.-X. Concurrent electropolymerization of aniline and electrochemical deposition of tungsten oxide for supercapacitor. J. Power Sources 2017, 342, 980-989. [CrossRef]

11. Liu, R.; Zhou, A.; Zhang, X.; Mu, J.; Che, H.; Wang, Y.; Wang, T.; Zhang, Z.; Kou, Z. Fundamentals, advances and challenges of transition metal compounds-based supercapacitors. Chem. Eng. J. 2021, 412, 128611. [CrossRef]

12. Guo, W.; Yu, C.; Li, S.; Wang, Z.; Yu, J.; Huang, H.; Qiu, J. Strategies and insights towards the intrinsic capacitive properties of $\mathrm{MnO}_{2}$ for supercapacitors: Challenges and perspectives. Nano Energy 2019, 57, 459-472. [CrossRef]

13. Miao, L.; Wang, J.; Zhang, P. Review on manganese dioxide for catalytic oxidation of airborne formaldehyde. Appl. Surf. Sci. 2019, 466, 441-453. [CrossRef]

14. Cao, Z.; Yang, Y.; Qin, J.; Su, Z. A core-shell porous $\mathrm{MnO}_{2}$ /Carbon nanosphere composite as the anode of lithium-ion batteries. J. Power Sources 2021, 491, 229577. [CrossRef]

15. Li, X.; Guo, R.; Huang, F.; Qi, W.; Liu, Y.; Cai, G.; Lin, J. An impedance biosensor based on magnetic nanobead net and $\mathrm{MnO}_{2}$ nanoflowers for rapid and sensitive detection of foodborne bacteria. Biosens. Bioelectron. 2021, 173, 112800.

16. Yu, H.; Chen, J.; Yang, K.; Zhang, Q.; Zhang, B. Tailoring carboxyl tubular carbon nanofibers $/ \mathrm{MnO}_{2}$ composites for highperformance lithium-ion battery anodes. J. Am. Ceram. Soc. 2020, 104, 1402-1414.

17. Kumar, R.; Matsuo, R.; Kishida, K.; Mohamed, M.; Abdel-Galeil, M.M.; Suda, Y.; Matsuda, A. Homogeneous reduced graphene oxide supported $\mathrm{NiO}-\mathrm{MnO}_{2}$ ternary hybrids for electrode material with improved capacitive performance. Electrochim. Acta 2019, 303, 246-256. [CrossRef]

18. Xie, A.; Tao, F.; Jiang, C.; Sun, W.; Li, Y.; Hu, L.; Du, X.; Luo, S.; Yao, C. A coralliform structured $\gamma-\mathrm{MnO} 2 /$ polyaniline nanocomposite for high performance supercapacitors. J. Electroanal. Chem. 2017, 789, 29-37. [CrossRef]

19. Sun, X.; Gan, M.; Ma, L.; Wang, H.; Zhou, T.; Wang, S.; Dai, W.; Wang, H. Fabrication of PANI-coated honeycomb-like MnO2 nanospheres with enhanced electrochemical performance for energy storage. Electrochim. Acta 2015, 180, 977-982. [CrossRef]

20. Li, G.; Huang, Z.; Chen, J.; Yao, F.; Liu, J.; Lun, L.; Sun, S.; Shi, Z. Rechargeable Zn-ion batteries with high power and energy densities: A two-electron reaction pathway in birnessite $\mathrm{MnO}_{2}$ cathode materials. J. Mater. Chem. A 2020, 8, 1975-1985. [CrossRef]

21. Ma, J.; Wang, J.; Dang, Y. Photo-assisted oxidation of gaseous benzene on tungsten-doped $\mathrm{MnO}_{2}$ at lower temperature. Chem. Eng. J. 2020, 388, 124387. [CrossRef]

22. Dinh, H.N.; Birss, V.I. Effect of Substrate on Polyaniline Film Properties A Cyclic Voltammetry and Impedance Study. J. Electrochem. Soc. 2019, 147, 3775-3784. [CrossRef]

23. Wen, T.; Huang, L.; Gopalan, A. Electrochemical Synthesis of a Polyaniline. J. Electrochem. Soc. 2019, 148, D9-D17. [CrossRef]

24. Bora, P.J.; Vinoy, K.J.; Ramamurthy, P.C.; Madras, G. Electromagnetic interference shielding efficiency of $\mathrm{MnO}_{2}$ nanorod doped polyaniline film. Mater. Res. Express 2017, 4, 025013. [CrossRef]

25. Mezgebe, M.M.; Xu, K.; Wei, G.; Guang, S.; Xu, H. Polyaniline wrapped manganese dioxide nanorods: Facile synthesis and as an electrode material for supercapacitors with remarkable electrochemical properties. J. Alloys Compd. 2019, 794, 634-644. [CrossRef]

26. Zhu, J.; He, J. Facile synthesis of Graphene-wrapped honeycomb $\mathrm{MnO}_{2}$ nanospheres and their application in supercapacitors. ACS Appl. Mater. Interfaces 2012, 4, 1770-1776. [CrossRef] [PubMed]

27. Liu, C.; Navale, S.T.; Yang, Z.B.; Galluzzi, M.; Patil, V.B.; Cao, P.J.; Mane, R.S.; Stadler, F.J. Ethanol gas sensing properties of hydrothermally grown $\alpha-\mathrm{MnO}_{2}$ nanorods. J. Alloys Compd. 2017, 727, 362-369. [CrossRef]

28. Palsaniya, S.; Nemade, H.B.; Dasmahapatra, A.K. Graphene based PANI/ $\mathrm{MnO}_{2}$ nanocomposites with enhanced dielectric properties for high energy density materials. Carbon 2019, 150, 179-190. [CrossRef]

29. Zhao, Y.; Wang, C. Extremely facile synthesis of manganese dioxide-polyaniline nano-reticulation with enhanced electrochemical properties. J. Alloys Compd. 2016, 677, 281-287. [CrossRef]

30. Yu, L.; Gan, M.; Ma, L.; Huang, H.; Hu, H.; Li, Y.; Tu, Y.; Ge, C.; Yang, F.; Yan, J. Facile synthesis of $\mathrm{MnO}_{2} /$ polyaniline nanorod arrays based on graphene and its electrochemical performance. Synth. Met. 2014, 198, 167-174. [CrossRef]

31. Jia, L.; Zheng, L.; Wang, W.; Shi, Y.; Zhang, Q.; Xu, X. Controllable design of coaxial $\mathrm{MnO}_{2} /$ polyaniline for asymmetric supercapacitors and stamping flexible micro-device. Mater. Lett. 2019, 252, 80-83. [CrossRef]

32. Kumar, R.; Youssry, S.M.; Ya, K.Z.; Tan, W.K.; Kawamura, G.; Matsuda, A. Microwave-assisted synthesis of $\mathrm{Mn}_{3} \mathrm{O}_{4}{ }^{-}$ $\mathrm{Fe}_{2} \mathrm{O}_{3} / \mathrm{Fe}_{3} \mathrm{O}_{4} @ \mathrm{rGO}$ ternary hybrids and electrochemical performance for supercapacitor electrode. Diam. Relat. Mater. 2020, 101, 107622. [CrossRef]

33. Wang, L.; Han, Y.; Feng, X.; Zhou, J.; Qi, P.; Wang, B. Metal-organic frameworks for energy storage: Batteries and supercapacitors. Coord. Chem. Rev. 2016, 307, 361-381. [CrossRef] 
34. Jafri, R.; Mishra, A.; Ramaprabhu, S. Polyaniline $\mathrm{MnO}_{2}$ nanotube hybrid nanocomposite as supercapacitor electrode material in acidic electrolyte. J. Mater. Chem. 2011, 21, 17601-17605.

35. Bao, X.; Zhang, Z.; Zhou, D. Pseudo-capacitive performance enhancement of $\alpha-\mathrm{MnO}_{2}$ via in situ coating with polyaniline. Synth Met. 2020, 260, 116271. [CrossRef]

36. Sun, D.; Wang, Z.; Huang, K.; Wang, X.; Wang, H.; Qing, C.; Wang, B.; Tang, Y. A sandwich-structured porous $\mathrm{MnO}_{2} /$ polyaniline $/ \mathrm{MnO}_{2}$ thin film for supercapacitor applications. Chem. Phys. Lett. 2015, 638, 38-42. [CrossRef] 